ENCYCIOPEDDE Encyclopédie berbère

BERBERE

$20 \mid 1998$

20 | Gauda - Girrei

\title{
Giddaba
}

(Mont) (voir C50, Chettaba, E.B., t. XII, p. 1905-1907 et E5, Edough,

E.B.,t. XVII, p. 2586-2588)

\section{El Briga}

\section{OpenEdition}

Journals

Édition électronique

URL : http://journals.openedition.org/encyclopedieberbere/1926

DOI : $10.4000 /$ encyclopedieberbere. 1926

ISSN : 2262-7197

Éditeur

Peeters Publishers

Édition imprimée

Date de publication : 1 octobre 1998

Pagination : 3127

ISBN : 2-7449-0028-1

ISSN : 1015-7344

Référence électronique

C. El Briga, « Giddaba », Encyclopédie berbère [En ligne], 20 | 1998, document G47, mis en ligne le 01 juin 2011 , consulté le 24 septembre 2020. URL : http://journals.openedition.org/encyclopedieberbere/ 1926 ; DOI : https://doi.org/10.4000/encyclopedieberbere.1926

Ce document a été généré automatiquement le 24 septembre 2020.

(c) Tous droits réservés 


\section{Giddaba}

(Mont) (voir C50, Chettaba, E.B., t. XII, p. 1905-1907 et E5, Edough, E.B.,t. XVII, p. 2586-2588)

\section{El Briga}

1 Mont que st Augustin cite trois fois, dans Johan. ad Parthos, 13 ; Sermo 45,7 et Epitr, 10*, 6,2. La mésaventure arrivée à des femmes giddabenses venues vendre du bois à Hippone, qui furent séquestrées par une habitante de cette ville avant d'être vendues à des marchands étrangers, montre que le Giddaba ne pouvait guère être très éloigné d'Hippone. St Augustin confirme implicitement cette proximité lorsqu'il qualifie cette montagne de "Giddaba noster".

2 Ces témoignages répétés de l'évêque d'Hippone font rejeter l'hypothèse de Mgr Toulotte qui pensait que le Chettaba, massif calcaire voisin de Cirta, avait conservé, en le déformant quelque peu, le nom antique de Giddaba. Dans une grotte du Chettaba avait lieu un pèlerinage annuel au cours duquel le magister de Phua dédicaçait une inscription à une divinité topique, évoquée seulement par les initiales GDAS. Dans la logique de son identification Giddaba = Chettaba, Mgr Toulotte proposait de développer le sigle GDAS en Giddabae Deo Augusto Sacrum. C'était oublier que le Chettaba porte un nom d'origine arabe.

3 Compte tenu des textes augustiniens, il est vraisemblable que le mont Giddaba se situait à proximité d'Hippone, que c'était un massif boisé, occupé par des Numides encore peu atteints par la culture urbaine. La partie orientale du massif de l'Edough, toute proche d'Annaba, nous semble convenir à cette identification.

INDEX

Mots-clés : Algérie, Géographie, Religion 